\title{
Feasibility of Identifying Patients at High Risk of Hereditary Gastric Cancer Based on Clinicopathological Variables
}

\author{
SADAAKI NISHIMURA ${ }^{1,2,3}$, MASAKAZU YASHIRO ${ }^{1,2,3}$, TOMOHIRO SERA ${ }^{1,2,3}$, YURIE YAMAMOTO ${ }^{2,3}$, \\ YUKAKO KUSHITANI ${ }^{1,2,3}$, ATSUSHI SUGIMOTO ${ }^{1,2,3}$, SHUHEI KUSHIYAMA ${ }^{1,2,3}$, KENJI KURODA ${ }^{1,2,3}$, \\ SHINGO TOGANO ${ }^{1,2,3}$, TOMOHISA OKUNO ${ }^{1,2,3}$, TATSURO TAMURA ${ }^{1}$, TAKAHIRO TOYOKAWA ${ }^{1}$, \\ HIROAKI TANAKA $^{1}$, KAZUYA MUGURUMA ${ }^{1}$, KOSEI HIRAKAWA ${ }^{1}$ and MASAICHI OHIRA ${ }^{1}$ \\ ${ }^{I}$ Department of Gastroenterological Surgery, Osaka City University Graduate School of Medicine, Osaka, Japan; \\ ${ }^{2}$ Molecular Oncology and Therapeutics, Osaka City University Graduate School of Medicine, Osaka, Japan; \\ ${ }^{3}$ Cancer Center for Translational Research, Osaka City University Graduate School of Medicine, Osaka, Japan
}

\begin{abstract}
Background/Aim: Multiplex gene panel tests using next-generation sequencing (NGS) are clinically available for gastric cancer $(G C)$. The NGS tests can reveal unexpected pathogenic variants to be associated with hereditary diseases, i.e., secondary genetic findings. We investigated whether GC patients at high risk of having hereditary gastric cancer (HGC) can be identified by their clinicopathological variables before they undergo NGS cancer gene panel tests. Patients and Methods: The cases of 2,286 patients with GC treated at our hospital during the years 1999-2017 were retrospectively analyzed; of them, 143 patients were identified as being at high risk of having $H G C$ (HR-HGC), and the remaining 2,143 patients were classified as having sporadic gastric cancer (SGC). Results: Compared to the SGC group, the HR-HGC status was significantly associated with younger age, female gender, macroscopic type IV and a histologically diffuse type. In a multivariate analysis, being young (i.e., $\leq 50$ years old) was an independent risk factor for HR-HGC. Conclusion: Female and young patients with diffuse-type GC are closely associated with a high risk of having $H G C$, and these factors might predict the detection of secondary genetic findings by NGS testing.
\end{abstract}

Gastric cancer (GC) is the fourth most common cause of death from malignant disease worldwide. The prognoses of patients with unresectable advanced or recurrent gastric cancer remain

Correspondence to: Masakazu Yashiro, MD, Ph.D., Department of Gastroenterological Surgery, Osaka City University Graduate School of Medicine, 1-4-3, Asahi-machi, Abeno-ku, Osaka City, Osaka 545-8585, Japan. Tel: +81 666453936, Fax: +81 666453935, e-mail:m9312510@med.osaka-cu.ac.jp

Key Words: Hereditary gastric cancer, diffuse-type, female. especially poor, with a median survival time of approximately 1 year among individuals receiving conventional therapy (1, 2 ). The development of drug resistance is a major obstacle in the treatment of gastric cancer, and only few effective therapies for combating chemoresistance are currently available. Multiplex gene panel tests using next-generation sequencing (NGS) are now clinically available for various cancers (including gastric cancer); these tests can identify actionable genetic alterations which might be treated with promising therapeutic drugs $(3,4)$.

The increasing use of NGS cancer gene panel tests can also reveal unexpected pathogenic variants that might contribute to hereditary diseases, as secondary genetic findings (5-7). Hereditary cancer (which occurs in multiple family members), representing approximately $2-10 \%$ of cancer patients, has been reported to be linked to a variety of germline mutations $(4,8,9)$. Therefore, it could be important to predict an individual patient's risk of developing hereditary cancer, including hereditary gastric cancer (HGC), before multiplex gene panel testing is conducted. We investigated whether GC patients at high risk of having HGC can be identified by their clinicopathologic variables before they undergo NGS cancer gene panel tests.

\section{Patients and Methods}

Patients and definition of high-risk hereditary gastric cancer. A total of 2286 treatment-naive patients with gastric cancer, who received gastrectomy between 1999 and 2017 at our department, were enrolled in this study. We classified the 2286 patients into two groups, a sporadic gastric cancer (SGC) group and a high-risk hereditary gastric cancer (HR-HGC) group, with reference to the modification of the International Gastric Cancer Linkage Consortium (IGCLC) criteria, as follows. We designated a new high-risk hereditary gastric cancer (HR-HGC) group with modification of the IGCLC criteria (10) to adapt the Japanese family configuration in this study, as follows: (a) patients under 40 
years old with gastric cancer, or (b) patients with two or more gastric cancer cases in first- or second-degree relatives regardless of their age, with unknown histologic type. Therefore, sporadic gastric cancers (SGCs) patients were defined as over 40 years of age and with one or no gastric cancer cases in their family (Figure 1). No patients under the age of 40 had a family history of gastric cancer in this study. Then, we assessed clinicopathologic factors between these groups.

Immunohistochemical determination of E-cadherin and p53. Among the 2286 patients, 720 cases with informed consent were examined for E-cadherin and p53 expression by immunostaining. The immunohistochemical determination of E-cadherin and p53 was performed as previously reported using anti-E-cadherin antibody (Dako, Carpinteria, CA, USA) and anti-p53 antibody (Santa Cruz, Dallas, TX, USA). In brief, we performed deparaffinization and slides were heated for $10 \mathrm{~min}$ at $105^{\circ} \mathrm{C}$ in an autoclave in Target Retrieval Solution (Dako). After blocking endogenous peroxidase activity, the specimens were incubated with E-cadherin antibody (1:100), and p53 antibody (DO-7; $1: 100)$ for $1 \mathrm{~h}$ at room temperature. Then, slides were incubated with biotinylated antimouse IgG for $10 \mathrm{~min}$, followed by treatment with streptavidinperoxidase reagent, and counterstaining with Mayer's hematoxylin. The expression of E-cadherin and p53 was analyzed by the intensity of staining and percentage of stained cancer cells. Positive p53 expression was evaluated in both malignant and normal tissues. Evaluation was made by two double-blinded independent observers who were unaware of the clinical data. When evaluation of the two independent observers was different, re-evaluation was performed to reach an agreement.

Statistical analysis. Correlations between each group and the clinicopathological factors were determined using the Chi-square test. Survival rates were estimated using the Kaplan-Meier method, and the differences in survival according to the group classification of patients were analyzed by log-rank test. Univariate and multivariate analyses were performed to determine significant risk factors associated with high-risk hereditary gastric cancer using Logistic regression models. The presence of a statistically significant difference was denoted by $p<0.05$. All analyses were performed using EZR (Saitama Medical Center, Jichi Medical University, Saitama, Japan), which is a graphical user interface for R (The R Foundation for Statistical Computing, Vienna, Austria) (11). More precisely, it is a modified version of $\mathrm{R}$ commander designed to add statistical functions frequently used in biostatistics.

\section{Results}

The clinicopathological features of HR-HGC patients compared to those of SGC patients. A total of 143 patients among 2,286 GC patients were identified as being HR-HGC according to our definition, and the remaining 2,143 patients were classified as having SGC (Figure 1). Table I summarizes the clinicopathological features of the HR-HGC and SGCs groups. The results of the multivariate analysis revealed that compared to the SGC group, the HR-HGC group had a significantly greater proportion of younger (i.e., $\leq 50$ years old) patients ( $8 \%$ vs. $48 \% ; p=0.001)$. The HRHGC status was also significantly correlated with female

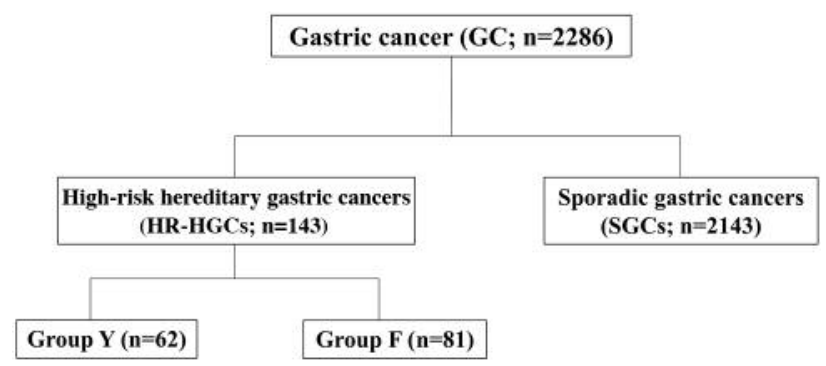

Figure 1. Patients and definition of high-risk hereditary gastric cancer. A total of 2,286 gastric cancer $(G C)$ patients were divided into two groups, a sporadic gastric cancer (SGC) group and a high-risk hereditary gastric cancer (HR-HGC) group. HR-HGC groups: Group $Y$ : patients with gastric cancer in an individual under 40 years old, and Group F: patients with two or more gastric cancer cases in first- or second-degree relatives regardless of their age. No patients under the age of 40 had a family history of gastric cancer in this study.

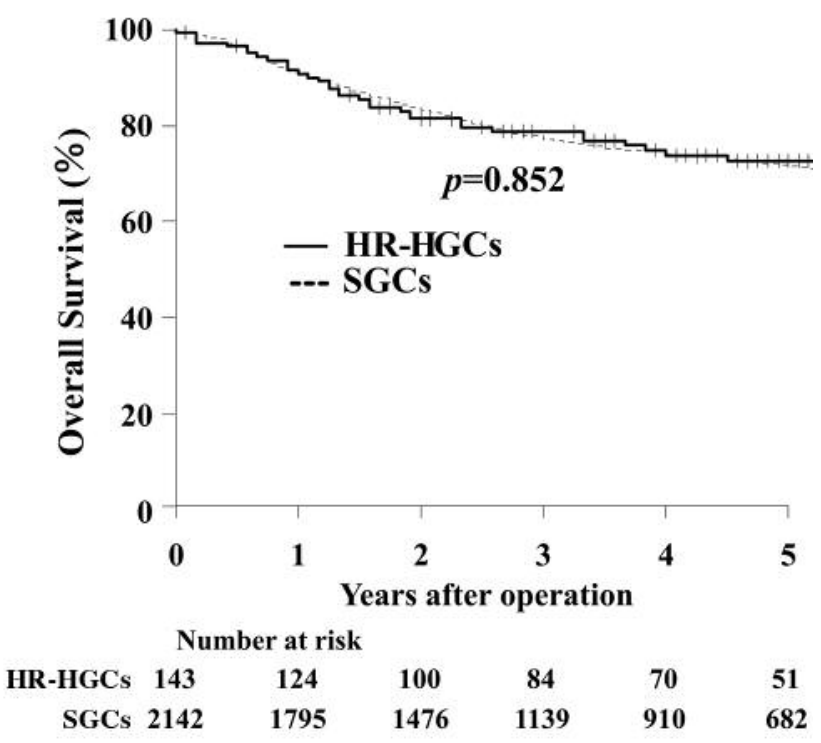

Figure 2. Overall survival of patients with gastric cancer. The KaplanMeier survival curve indicated that the overall survival of patients with $H R-H G C s$ and SGCs was not different.

gender $(43 \%$ vs. $30 \% ; p=0.004)$, macroscopic type IV $(11 \%$ $v s .7 \% ; p=0.001)$, and histologic diffuse type $(63 \% v s .48 \%$; $p=0.001)$ compared to the SGC patients. No significant between-group difference was observed regarding nodal involvement, distant metastasis, lymphatic invasion, or venous invasion (Table I). There were no significant differences in the 5-year survival rate between the HR-HGC and SGC patients (Figure 2). 
Table I. Patient demographics in resected cases according to the classification in this study.

\begin{tabular}{|c|c|c|c|}
\hline & *HR-HGCs & $* *$ SGCs & $p$-Value \\
\hline Variables $(\%)$ & $143(6)$ & $2143(94)$ & \\
\hline \multicolumn{4}{|l|}{ Gender } \\
\hline Male (69) & $82(57)$ & $1487(70)$ & \\
\hline Female (31) & $61(43)$ & $656(30)$ & 0.004 \\
\hline \multicolumn{4}{|l|}{ Age } \\
\hline$\leq 50(10)$ & $68(48)$ & $162(8)$ & \\
\hline$>50(90)$ & $75(52)$ & $1981(92)$ & $<0.001$ \\
\hline \multicolumn{4}{|l|}{ Macroscopic type } \\
\hline Other (96) & $128(89)$ & $1999(93)$ & \\
\hline IV (4) & $15(11)$ & $144(7)$ & $<0.001$ \\
\hline \multicolumn{4}{|l|}{ Pathogenic type } \\
\hline Diffuse-type (48) & $90(63)$ & $1018(48)$ & \\
\hline Intestinal-type (52) & $53(37)$ & $1125(52)$ & $<0.001$ \\
\hline \multicolumn{4}{|l|}{ Primary tumor } \\
\hline $\mathrm{T} 1(50)$ & $74(52)$ & $1067(50)$ & \\
\hline $\mathrm{T} 2-4(50)$ & $69(48)$ & $1076(50)$ & 0.667 \\
\hline \multicolumn{4}{|l|}{ Nodal involvement } \\
\hline Positive (39) & $63(42)$ & $833(39)$ & \\
\hline Negative (61) & $80(58)$ & $1310(61)$ & 0.25 \\
\hline \multicolumn{4}{|l|}{ Distant metastasis } \\
\hline Positive (11) & $21(15)$ & $241(11)$ & \\
\hline Negative (89) & $122(85)$ & $1902(89)$ & 0.221 \\
\hline \multicolumn{4}{|l|}{ Clinical stage } \\
\hline I, II (71) & $99(69)$ & $1512(71)$ & \\
\hline III, IV (29) & $44(31)$ & $630(29)$ & 0.776 \\
\hline \multicolumn{4}{|l|}{ Lymphatic invasion } \\
\hline Positive (49) & $68(48)$ & $1056(49)$ & \\
\hline Negative (51) & $75(52)$ & $1087(51)$ & 0.73 \\
\hline \multicolumn{4}{|l|}{ Venous invasion } \\
\hline Positive (18) & $23(16)$ & $384(18)$ & \\
\hline Negative (82) & $120(84)$ & $1759(82)$ & 0.652 \\
\hline \multicolumn{4}{|c|}{ E-cadherin expression $n=720$} \\
\hline Positive (54) & $29(58)$ & $359(54)$ & \\
\hline Negative (46) & $21(42)$ & $311(46)$ & 0.561 \\
\hline
\end{tabular}

*High-Risk Hereditary Gastric Cancers, including Group Y and F; ** Sporadic Gastric Cancers.

Sixty-two of the 143 patients in the HR-HGC group were $<40$ years old (group Y, for 'younger'), and the remaining 81 patients had a family history of gastric cancer (group F, for 'family history') (Figure 1). No patients under the age of 40 had a family history of gastric cancer. Table II shows a comparison of the clinicopathologic features between group $\mathrm{Y}$ and group F. Compared to group F patients, group Y patients had significant correlations with macroscopic type IV $(p=0.025)$, histologically diffuse type $(p<0.001)$, high invasion depth $(p=0.044)$, and distant metastasis $(p=0.008)$. Group Y was significantly younger compared to group $\mathrm{F}(p<0.001)$. Figure 3 illustrates the 5-year survival of the group $\mathrm{Y}$ and $\mathrm{F}$ patients: among the Stage I patients, the 5-year survival of group $\mathrm{Y}$ was significantly better than that of group $\mathrm{F}$.
Table II. Patient demographics in resected cases between group $Y$ and $F$.

\begin{tabular}{|c|c|c|c|}
\hline & *Group Y & $* *$ Group F & $p$-Value \\
\hline Variables $(\%)$ & $62(46)$ & $81(53)$ & \\
\hline \multicolumn{4}{|l|}{ Gender } \\
\hline Male (57) & $30(49)$ & $52(64)$ & \\
\hline Female (43) & $32(51)$ & $29(36)$ & 0.063 \\
\hline \multicolumn{4}{|l|}{ Age } \\
\hline $50[35-68]^{\dagger}$ & $34[30-37]$ & $68[60-73]$ & $<0.001$ \\
\hline \multicolumn{4}{|l|}{ Macroscopic type } \\
\hline Other (90) & $51(82)$ & $47(95)$ & \\
\hline IV $(10)$ & $11(18)$ & $4(5)$ & 0.025 \\
\hline \multicolumn{4}{|l|}{ Pathogenic type } \\
\hline Diffuse-type (63) & $57(92)$ & $33(41)$ & \\
\hline Intestinal-type (37) & $5(8)$ & $48(59)$ & $<0.001$ \\
\hline \multicolumn{4}{|l|}{ Primary tumor } \\
\hline $\mathrm{T} 1(52)$ & $26(42)$ & $48(59)$ & \\
\hline $\mathrm{T} 2-4(48)$ & $36(58)$ & $33(41)$ & 0.044 \\
\hline \multicolumn{4}{|l|}{ Nodal involvement } \\
\hline Positive (44) & $28(45)$ & $35(43)$ & \\
\hline Negative (56) & $34(55)$ & $46(57)$ & 0.866 \\
\hline \multicolumn{4}{|l|}{ Distant metastasis } \\
\hline Positive (15) & $15(24)$ & $6(7)$ & \\
\hline Negative (85) & $47(76)$ & $75(93)$ & 0.008 \\
\hline \multicolumn{4}{|l|}{ Pathological stage } \\
\hline I,II (69) & $37(60)$ & $62(77)$ & \\
\hline III,IV (31) & $25(40)$ & $19(24)$ & 0.044 \\
\hline \multicolumn{4}{|l|}{ Lymphatic invasion } \\
\hline Positive (48) & $29(47)$ & $39(48)$ & \\
\hline Negative (52) & $33(53)$ & $42(52)$ & 1 \\
\hline \multicolumn{4}{|l|}{ Venous invasion } \\
\hline Positive (16) & $9(13)$ & $14(17)$ & \\
\hline Negative (84) & $53(87)$ & $67(83)$ & 0.819 \\
\hline \multicolumn{4}{|c|}{ E-cadherin expression $n=50$} \\
\hline Positive (58) & $12(50)$ & $17(65)$ & \\
\hline Negative (42) & $12(50)$ & $9(35)$ & 0.39 \\
\hline
\end{tabular}

*Group $\mathrm{Y}$ indicates gastric cancer in an individual under the age of 40 . **Group $\mathrm{F}$ indicates two gastric cancer cases in a family regardless of age, at least one confirmed first degree relative. ${ }^{\dagger}$ Values are median [interquartile range].

In the univariate analysis of risk factors for HR-HGC, the significant risk factors for HR-HGC were being young, and being female having diffuse-type microscopic findings $(p<0.001, p<0.001$, respectively; Table III). In the multivariate analysis, being a young patient was an independent risk factor for HR-HGC (odds ratio=10.3, $p<0.001$; Table III).

Immunohistochemical determination of E-cadherin and p53. E-cadherin was positive in 388 of 720 cases (Tables I and II). No significant correlation was observed between E-cadherin loss and the HR-HGC status. In contrast, p53 expression was detected in 271 of 720 cases of tumor cells (data not shown), but there was no case with p53-positive staining in normal cells (Figure 4). 
A

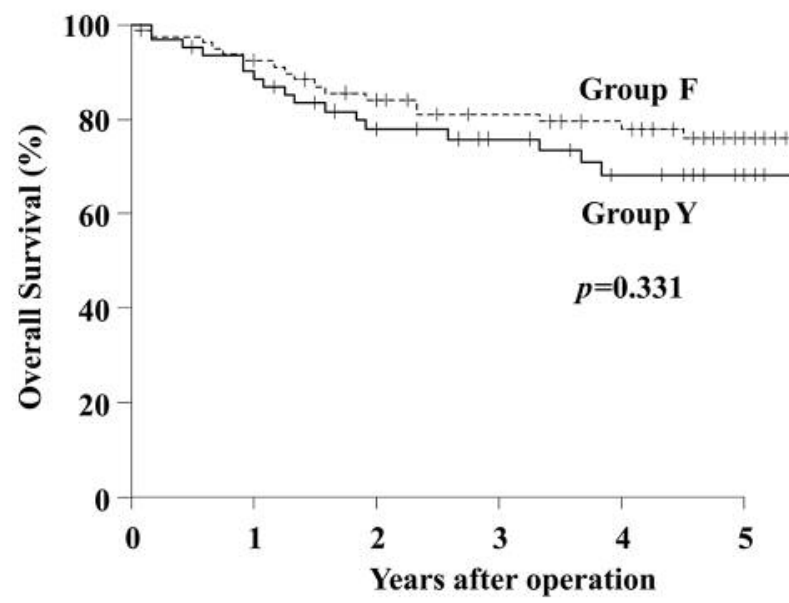

\begin{tabular}{ccccccc}
\multicolumn{8}{c}{ Number at risk } \\
Group Y & $\mathbf{6 2}$ & $\mathbf{5 4}$ & $\mathbf{4 1}$ & $\mathbf{3 3}$ & $\mathbf{2 3}$ & $\mathbf{1 8}$ \\
Group F & $\mathbf{8 1}$ & $\mathbf{7 0}$ & $\mathbf{5 9}$ & $\mathbf{5 1}$ & $\mathbf{4 7}$ & $\mathbf{3 3}$
\end{tabular}

\section{B pStage I}

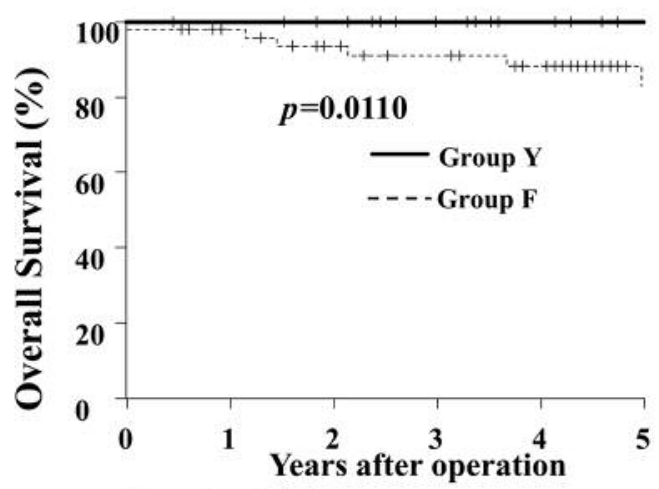
Number at risk

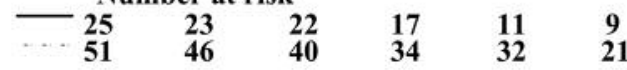

\section{pStage III}

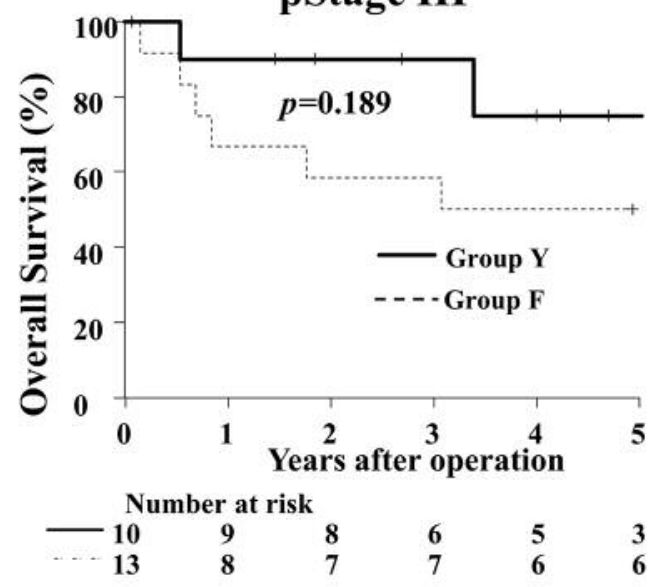

\section{pStage II}
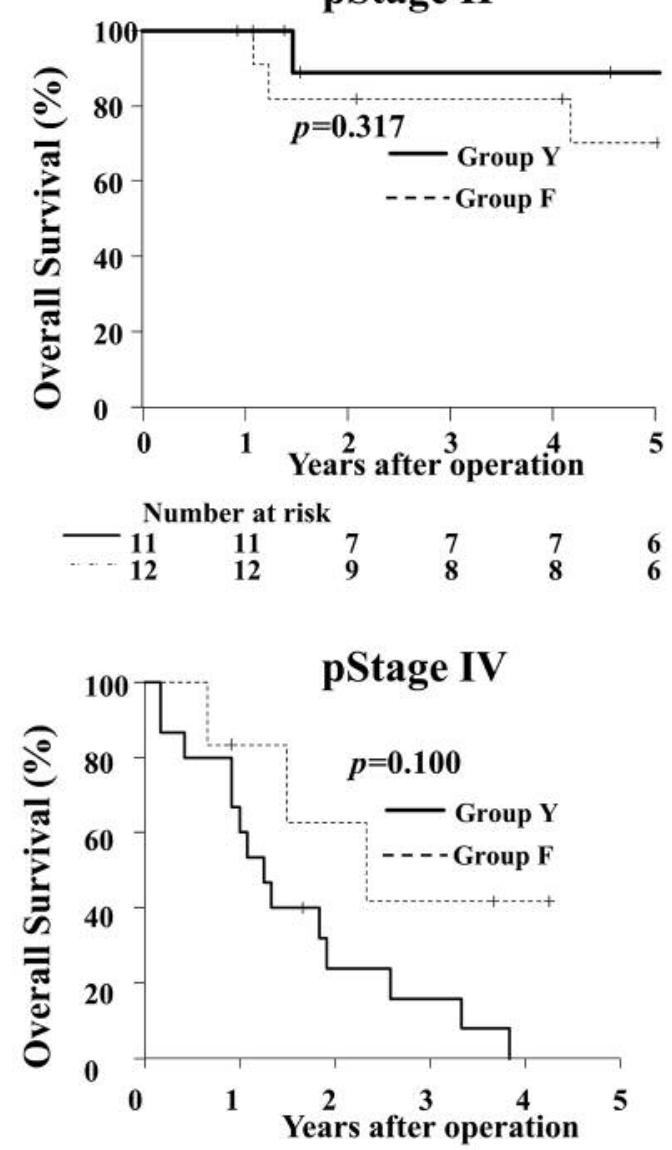

\begin{tabular}{cccccc}
\multicolumn{2}{c}{ Number at risk } \\
-15 & 10 & 3 & 2 & 0 & 0 \\
6 & 4 & 3 & 2 & 1 & 0
\end{tabular}

Figure 3. Overall survival of patients with HR-HGCs. A) Overall survival in HR-HGCs and SGCs was not different between Group Y and Group F. $B)$ The Kaplan-Meier survival curve indicated that the overall survival of patients of Group Y was significantly better $(p=0.0110)$ than that of Group F patients at pStage I. 


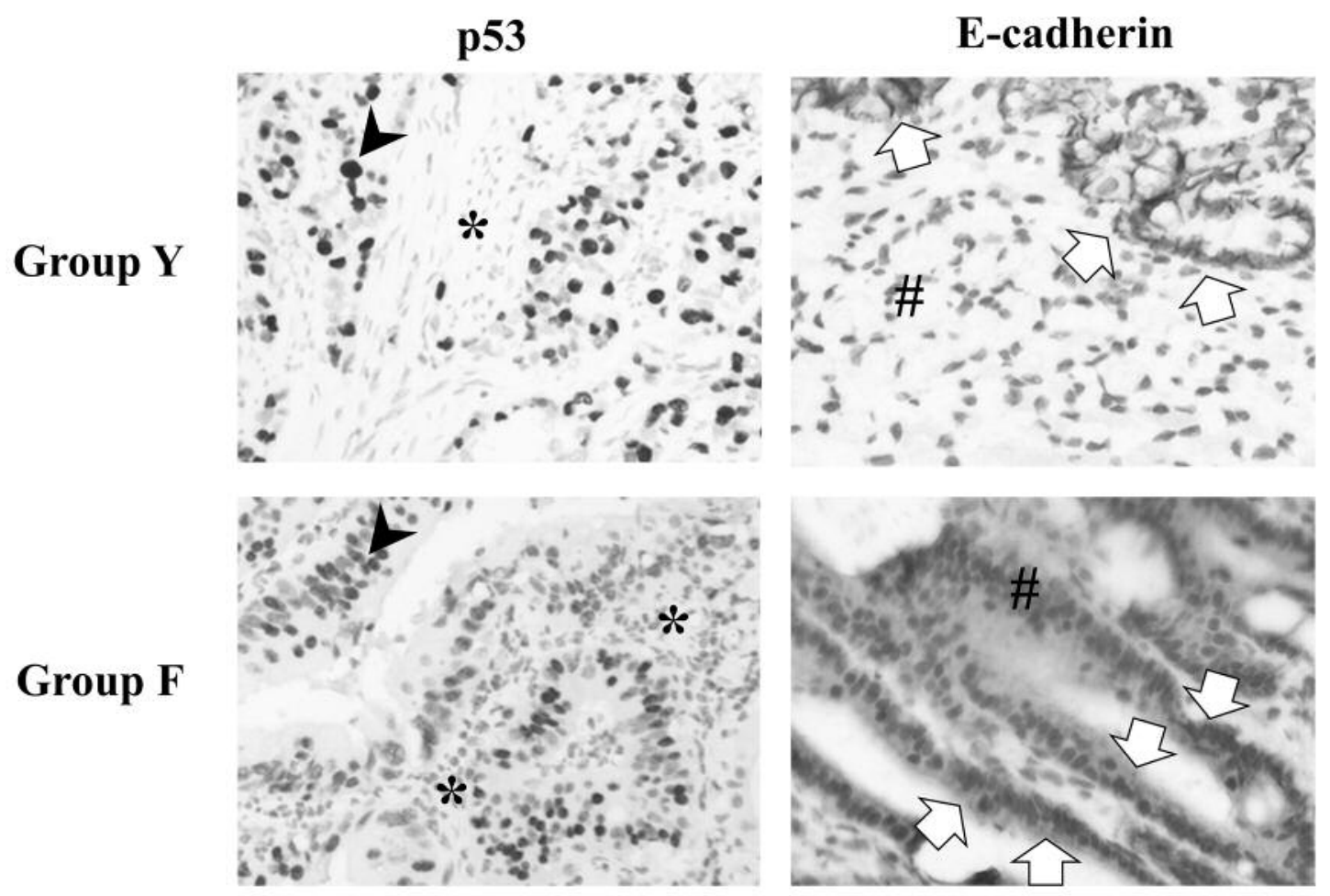

Figure 4. Representative pictures of p53 staining and E-cadherin staining. Cancer cells were positive for p53 staining (black arrow head), but not normal cells (asterisk) in both group $Y$ case and group $F$ case. E-cadherin expression of cancer cells was weak or lost (pound), whereas normal cells were positive (white thick arrow) in both group Y case and group F case. (Magnification; $\times 200$ ).

Table III. Univariable and multivariable analyses for risk factor of high risk hereditary gastric cancer in 2,286 patients.

\begin{tabular}{|c|c|c|c|c|c|c|}
\hline \multirow[b]{2}{*}{ Variables } & \multicolumn{3}{|c|}{ Univariable analysis } & \multicolumn{3}{|c|}{ Multivariable analysis } \\
\hline & Odds ratio & $95 \% \mathrm{CI}$ & $p$-Value & Odds ratio & $95 \% \mathrm{CI}$ & $p$-Value \\
\hline Age $(\leq 50)$ & 11.1 & $7.69-16.0$ & $<0.001$ & 10.3 & $7.11-15.0$ & $<0.001$ \\
\hline Female and Diffuse-type & 2.15 & $1.49-3.10$ & $<0.001$ & 1.43 & $0.96-2.13$ & 0.078 \\
\hline Macroscopic type (type IV) & 1.69 & $0.93-2.85$ & 0.090 & & & \\
\hline Primary tumor $(\mathrm{T} 4)$ & 1.04 & $0.71-1.52$ & 0.832 & & & \\
\hline Nodal involvement (Positive) & 1.23 & $0.88-1.74$ & 0.223 & & & \\
\hline Distant metastasis (Positive) & 1.36 & $0.84-2.20$ & 0.213 & & & \\
\hline Pathological Stage (III, IV) & 1.07 & $0.74-1.54$ & 0.730 & & & \\
\hline Lymphatic invasion (Positive) & 0.93 & $0.66-1.31$ & 0.690 & & & \\
\hline Venous invasion (Positive) & 0.88 & $0.55-1.39$ & 0.580 & & & \\
\hline
\end{tabular}

\section{Discussion}

In this study, we designated a new HR-HGC group with a modification of the IGCLC criteria (10) to adapt the criteria to Japanese family configuration, as follows: (a) gastric cancer patient $<40$ years old, or (b) patients with two or more gastric cancer cases in first- or second-degree relatives. Approximately
$6 \%$ of the GC patients in our present series were classified into the HR-HGC group, and this value is in agreement with the report (8) related to familial GC (ranging from 5\% to 10\%). Our analyses revealed that histological diffuse-type, female gender, and younger age were closely associated with being at high risk of having HGC, suggesting that these three factors could be valuable for identifying patients at high risk of having HGC. 
The histological diffuse-type was one of the factors associated with HR-HGC. It has been reported that diffusetype GC is closely associated with a low expression of $\mathrm{CDH} 1$, which is also known as E-cadherin $(12,13)$. Based on those findings, a germline alteration in $C D H 1$ was identified as a causative mechanism of HGC, namely hereditary diffuse gastric cancer, mainly in European and New Zealand Maori patients $(10,14,15)$. A germline $C D H 1$ alteration in HGC is extremely rare in Japan, whereas a germline alteration in $\mathrm{CDH} 1$ was identified in approx. $22-50 \%$ of European patients who match the HGC criteria of $\operatorname{IGCLC}(10,16)$.

In our present Japanese patient population, there was no significant correlation with E-cadherin expression levels in the HR-HGC or SGC groups. No other germline mutation in a different gene has been associated with GC $(17,18)$. After the discovery of a rare germline mutation in HGC, Yamada et al. suggested that an unidentified germline mutation responsible for familial GC may be present in Japanese patients (16). Multiplex gene panel tests might detect unknown pathogenic variants to be linked to hereditary diseases, even when secondary genetic findings are not expected.

We observed that female gender is one of the most significant factors for being at high risk of having HGC, but the impact of sex-linked genes on hereditary cancer is still uncertain. Most of the identified genes responsible for hereditary cancer are located on the autosomes, not the sex chromosomes $(10,19-21)$, but some X-chromosome genes were recently reported to be associated with female-specific cancers, such as ovarian cancer and to be correlated with hereditary diseases (22-24). X-chromosome studies might help clarify the molecular mechanisms underlying the correlation between female gender and hereditary GC.

Young age (i.e., <50 years) was also demonstrated to be an independent factor for HR-HGC by the present study's multivariate analysis. None of our patients under the age of 40 had a family history of gastric cancer. In two prior investigations, $7.3 \%$ to $25 \%$ of young patients had a family history of gastric cancer $(25,26)$. It is well known that young age of onset is a risk factor of hereditary cancer (27), but it can be difficult to diagnose HGC in individuals <40 years old, because GC does not have a clear precancerous lesion such as colorectal polyposis. Compared to other hereditary cancers with a precancerous lesion, HGC may show different clinical characteristics at different patients' ages.

The prognoses of the present study's HR-HGC patients was not significantly different from those of the patients with SGC, which is similar to previous reports $(28,29)$. In contrast, the 5-year survival rate of the patients $<40$ years old (group Y) was significantly better than that of patients with a family history of gastric cancer (group F) only among the patients with Stage I cancer. This significant difference might be due to a younger patient's age at the detection of gastric cancer at an early stage.
In conclusion, female and young patients with histological diffuse-type gastric cancer are closely associated with a high risk of having HGC. Female, young, histological diffuse-type gastric cancer might predict the detection of secondary genetic findings by NGS gene panel tests for gastric cancer patients.

\section{Conflict of Interest}

There are no financial or other interests with regard to the submitted manuscript that might be construed as a conflict of interest.

\section{Authors' Contributions}

SN: Study conception and design, acquisition of data, analysis and interpretation of data, drafting manuscript; MY: study conception and design, acquisition of data, analysis and interpretation of data, drafting manuscript; Drafting and revisiting manuscript, and interpretation of the results: TS, YY, YK, AS, ST, KK, TO, TT, TT, HT, KM, KH, MO.

\section{Acknowledgements}

This study was partially founded by KAKENHI Grant-in-Aid for Scientific Research, Nos. 18H02883(M.Y.).

\section{References}

1 Ohtsu A, Shah MA, Van Cutsem E, Rha SY, Sawaki A, Park SR, Lim HY, Yamada Y, Wu J, Langer B, Starnawski M and Kang YK: Bevacizumab in combination with chemotherapy as firstline therapy in advanced gastric cancer: A randomized, doubleblind, placebo-controlled phase III study. J Clin Oncol 29(30): 3968-3976, 2011. PMID: 21844504. DOI: 10.1200/JCO.2011 .36 .2236

2 Bang YJ, Van Cutsem E, Feyereislova A, Chung HC, Shen L, Sawaki A, Lordick F, Ohtsu A, Omuro Y, Satoh T, Aprile G, Kulikov E, Hill J, Lehle M, Ruschoff $J$ and Kang YK: Trastuzumab in combination with chemotherapy versus chemotherapy alone for treatment of her2-positive advanced gastric or gastro-oesophageal junction cancer (toga): A phase 3, open-label, randomised controlled trial. Lancet 376(9742): 687697, 2010. PMID: 20728210. DOI: 10.1016/S0140-6736(10) 61121-X

3 Cancer Genome Atlas Research Network: Comprehensive molecular characterization of gastric adenocarcinoma. Nature 513(7517): 202-209, 2014. PMID: 25079317. DOI: 10.1038/ nature 13480

4 Glodkowska-Mrowka E and Stoklosa T: Chapter 4 - next generation sequencing in oncology. In: Clinical applications for next-generation sequencing. Demkow U and Płoski R (eds.). Academic Press: Boston, pp. 63-74, 2016.

5 Kurian AW, Hare EE, Mills MA, Kingham KE, McPherson L, Whittemore AS, McGuire V, Ladabaum U, Kobayashi Y, Lincoln SE, Cargill M and Ford JM: Clinical evaluation of a multiplegene sequencing panel for hereditary cancer risk assessment. J Clin Oncol 32(19): 2001-2009, 2014. PMID: 24733792. DOI: $10.1200 /$ jco.2013.53.6607 
6 Thompson ER, Rowley SM, Li N, McInerny S, Devereux L, Wong-Brown MW, Trainer AH, Mitchell G, Scott RJ, James PA and Campbell IG: Panel testing for familial breast cancer: Calibrating the tension between research and clinical care. J Clin Oncol 34(13): 1455-1459, 2016. PMID: 26786923. DOI: 10.1200/jco.2015.63.7454

7 Couch FJ, Shimelis H, Hu C, Hart SN, Polley EC, Na J, Hallberg E, Moore R, Thomas A, Lilyquist J, Feng B, McFarland R, Pesaran T, Huether R, LaDuca H, Chao EC, Goldgar DE and Dolinsky JS: Associations between cancer predisposition testing panel genes and breast cancer. JAMA Oncol 3(9): 1190-1196, 2017. PMID: 28418444. DOI: 10.1001/ jamaoncol.2017.0424

8 Guilford P, Humar B and Blair V: Hereditary diffuse gastric cancer: Translation of cdh1 germline mutations into clinical practice. Gastric Cancer 13(1): 1-10, 2010. PMID: 20373070. DOI: $10.1007 / \mathrm{s} 10120-009-0531-\mathrm{x}$

9 Lowry PA: Late issues for patients who survive the initial diagnosis and treatment of cancer. In: Decision making in medicine (third edition). Mushlin SB and Greene HL (eds.). Mosby: Philadelphia, pp. 286-289, 2010.

10 van der Post RS, Vogelaar IP, Carneiro F, Guilford P, Huntsman D, Hoogerbrugge N, Caldas C, Schreiber KE, Hardwick RH, Ausems MG, Bardram L, Benusiglio PR, Bisseling TM, Blair V, Bleiker E, Boussioutas A, Cats A, Coit D, DeGregorio L, Figueiredo J, Ford JM, Heijkoop E, Hermens R, Humar B, Kaurah P, Keller G, Lai J, Ligtenberg MJ, O’Donovan M, Oliveira C, Pinheiro H, Ragunath K, Rasenberg E, Richardson S, Roviello F, Schackert H, Seruca R, Taylor A, Ter Huurne A, Tischkowitz M, Joe ST, van Dijck B, van Grieken NC, van Hillegersberg R, van Sandick JW, Vehof R, van Krieken JH and Fitzgerald RC: Hereditary diffuse gastric cancer: Updated clinical guidelines with an emphasis on germline cdh1 mutation carriers. J Med Genet 52(6): 361-374, 2015. PMID: 25979631. DOI: $10.1136 /$ jmedgenet-2015-103094

11 Kanda Y: Investigation of the freely available easy-to-use software 'ezr' for medical statistics. Bone Marrow Transplant 48(3): 452458, 2013. PMID: 23208313. DOI: 10.1038/bmt. 2012.244

12 Fang WL, Chang SC, Lan YT, Huang KH, Lo SS, Li AF, Chi CW, $\mathrm{Wu} \mathrm{CW}$ and Chiou SH: Molecular and survival differences between familial and sporadic gastric cancers. Biomed Res Int 2013: 396272, 2013. PMID: 23555086. DOI: $10.1155 / 2013 / 396272$

13 Yashiro M, Chung YS, Nishimura S, Inoue T and Sowa M: Establishment of two new scirrhous gastric cancer cell lines: Analysis of factors associated with disseminated metastasis. $\mathrm{Br}$ J Cancer 72(5): 1200-1210, 1995. PMID: 7577468. DOI: 10.10 38/bjc. 1995.486

14 Oliveira C, Pinheiro H, Figueiredo J, Seruca R and Carneiro F: Familial gastric cancer: Genetic susceptibility, pathology, and implications for management. Lancet Oncol 16(2): E60-E70, 2015. PMID: 25638682. DOI: 10.1016/s1470-2045(14)71016-2

15 Oliveira C, Seruca R and Carneiro F: Hereditary gastric cancer. Best Pract Res Clin Gastroenterol 23(2): 147-157, 2009. PMID: 19414142. DOI: 10.1016/j.bpg.2009.02.003

16 Yamada H, Shinmura K, Ito H, Kasami M, Sasaki N, Shima H, Ikeda M, Tao H, Goto M, Ozawa T, Tsuneyoshi T, Tanioka F and Sugimura H: Germline alterations in the cdh1 gene in familial gastric cancer in the japanese population. Cancer Sci 102(10): 1782-1788, 2011. PMID: 21777349. DOI: 10.1111/j.13497006.2011.02038.x
17 Fewings E, Larionov A, Redman J, Goldgraben MA, Scarth J, Richardson S, Brewer C, Davidson R, Ellis I, Evans DG, Halliday D, Izatt L, Marks P, McConnell V, Verbist L, Mayes R, Clark GR, Hadfield J, Chin SF, Teixeira MR, Giger OT, Hardwick R, di Pietro M, O’Donovan M, Pharoah P, Caldas C, Fitzgerald $\mathrm{RC}$ and Tischkowitz M: Germline pathogenic variants in palb2 and other cancer-predisposing genes in families with hereditary diffuse gastric cancer without cdh1 mutation: A whole-exome sequencing study. Lancet Gastroenterol Hepatol 3(7): 489-498, 2018. PMID: 29706558. DOI: 10.1016/s24681253(18)30079-7

18 Weren RDA, van der Post RS, Vogelaar IP, van Krieken JH, Spruijt L, Lubinski J, Jakubowska A, Teodorczyk U, Aalfs CM, van Hest LP, Oliveira C, Kamping EJ, Schackert HK, Ranzani GN, Garcia EBG, Hes FJ, Holinski-Feder E, Genuardi M, Ausems M, Sijmons RH, Wagner A, van der Kolk LE, Cats A, Bjornevoll I, Hoogerbrugge $\mathrm{N}$ and Ligtenberg MJL: Role of germline aberrations affecting ctnna1, map3k6 and myd88 in gastric cancer susceptibility. J Med Genet 55(10): 669-674, 2018. PMID: 29330337. DOI: 10.1136/jmedgenet-2017104962

19 Malkin D: Li-fraumeni syndrome. Genes Cancer 2(4): 475-484, 2011. PMID: 21779515. DOI: 10.1177/1947601911413466

20 Moreira L, Balaguer F, Lindor N, de la Chapelle A, Hampel H, Aaltonen LA, Hopper JL, Le Marchand L, Gallinger S, Newcomb PA, Haile R, Thibodeau SN, Gunawardena S, Jenkins MA, Buchanan DD, Potter JD, Baron JA, Ahnen DJ, Moreno V, Andreu M, Ponz de Leon M, Rustgi AK and Castells A: Identification of lynch syndrome among patients with colorectal cancer. JAMA 308(15): 1555-1565, 2012. PMID: 23073952. DOI: $10.1001 /$ jama.2012.13088

21 Kurian AW, Ward KC, Howlader N, Deapen D, Hamilton AS, Mariotto A, Miller D, Penberthy LS and Katz SJ: Genetic testing and results in a population-based cohort of breast cancer patients and ovarian cancer patients. J Clin Oncol 37(15): 1305-1315, 2019. PMID: 30964716. DOI: 10.1200/jco.18.01854

22 Spatz A, Borg C and Feunteun J: X-chromosome genetics and human cancer. Nat Rev Cancer 4(8): 617-629, 2004. PMID: 15286741, DOI: $10.1038 / \mathrm{nrc} 1413$

23 Winham SJ, Larson NB, Armasu SM, Fogartyl ZC, Larson MC, McCauley BM, Wang C, Lawrenson K, Gayther S, Cunningham JM, Fridley BL and Goode EL: Molecular signatures of $\mathrm{x}$ chromosome inactivation and associations with clinical outcomes in epithelial ovarian cancer. Hum Mol Genet 28(8): 1331-1342, 2019. PMID: 30576442. DOI: $10.1093 / \mathrm{hmg} / \mathrm{ddy} 444$

24 Gao S, Jiang Y, Wang G, Yuan Y, Huang S, Gao X, Li X, Zhang D, Wu J, Ji X, Deng T, Wang L, Kang D and Dai P: Skewed $\mathrm{x}$-chromosome inactivation and next-generation sequencing to identify a novel smpx variants associated with $\mathrm{x}$-linked hearing loss in a chinese family. Int $\mathrm{J}$ Pediatr Otorhinolaryngol 113: 88-93, 2018. PMID: 30174017. DOI: 10.1016/j.ijporl.2018.07.022

25 Zhou F, Shi J, Fang C, Zou XP and Huang Q: Gastric carcinomas in young (younger than 40 years) chinese patients clinicopathology, family history, and postresection survival. Medicine 95(9): 11, 2016. PMID: 26945372. DOI: 10.1097/md. 0000000000002873

26 Braga-Neto MB, Carneiro JG, Barbosa AMD, Silva IS, Maia DC, Maciel FS, de Alcantara RJA, Vasconscelos PRL and Braga 
L: Clinical characteristics of distal gastric cancer in young adults from northeastern brazil. BMC Cancer 18: 7, 2018. PMID: 2940 2219. DOI: $10.1186 / \mathrm{s} 12885-018-3995-4$

27 Frank C, Fallah M, Sundquist J, Hemminki A and Hemminki K: Population landscape of familial cancer. Sci Rep 5: 12891, 2015. PMID: 26256549. DOI: 10.1038/srep12891

28 Hsieh FJ, Wang YC, Hsu JT, Liu KH, Yeh CN, Yeh TS, Hwang TL and Jan YY: Clinicopathological features and prognostic factors of gastric cancer patients aged 40 years or younger. J Surg Oncol 105(3): 304-309, 2012. PMID: 22116742. DOI: $10.1002 /$ jso.22084
29 Jeong O, Jung MR, Park YK and Ryu SY: Clinicopathological features and survival of patients with gastric cancer with a family history: A large analysis of 2,736 patients with gastric cancer. J Gastric Cancer 17(2): 162-172, 2017. PMID: 2868 0721. DOI: $10.5230 /$ jgc.2017.17.e20

Received June 29, 2019

Revised July 15, 2019

Accepted July 16, 2019 